\title{
COLORECTAL CANCER IN YOUNG PATIENTS: A CASE REPORT
}

Clin Biomed Res. 2016;36(2):110-113

1 Serviço de Oncologia, Hospital de Clínicas de Porto Alegre. Porto Alegre, RS, Brazil.

2 Serviço de Gastroenterologia, Hospital de Clínicas de Porto Alegre. Porto Alegre, RS, Brazil.

3 Serviço de Medicina Interna, Hospital de Clínicas de Porto Alegre. Porto Alegre, RS, Brazil.

4 Residência em Clínica Médica, Hospital de Clínicas de Porto Alegre. Porto Alegre, RS, Brazil.

5 Serviço de Medicina Intensiva, Hospital de Clínicas de Porto Alegre. Porto Alegre, RS, Brazil.

6 Serviço de Endocrinologia, Hospital de Clínicas de Porto Alegre. Porto Alegre, RS, Brazil.

7 Departamento de Medicina Interna, Faculdade de Medicina, Universidade Federal do Rio Grande do Sul (UFRGS). Porto Alegre, RS, Brazil.

8 Programa de Pós-graduação em Endocrinologia, Faculdade de Medicina, Universidade Federal do Rio Grande do Sul (UFRGS). Porto Alegre, RS, Brazil.

Corresponding author: Taiane Francieli Rebelatto taiarebelatto@hotmail.com Serviço de Oncologia, Hospital de Clínicas de Porto Alegre Rua Ramiro Barcelos, 2350, sala 700 90035-903, Porto Alegre, RS, Brazil.

\author{
Taiane Francieli Rebelatto ${ }^{1}$, Luiza Haendchen Bento², \\ Rafaela Fenalti Salla ${ }^{3}$, Lucas Pires Ries ${ }^{3}$, \\ Felipe Augusto Almeida ${ }^{4}$, Barbara Rayanne Fior ${ }^{5}$, Roberta Marobin ${ }^{6}$, \\ Luciane Restelatto ${ }^{5}$, Simone Wajner ${ }^{7,8}$
}

Colorectal cancer is the third most common malignant neoplasm worldwide, predominantly affecting the elderly population. However, in recent decades, there has been an increase in its incidence in patients under 50 years of age, who currently represent $7-26 \%$ of the diagnosed cases $^{1-3}$.

In this age group, the clinical presentation is similar to that of patients over 50. A previous prevalence study with young patients showed that the most common symptoms are rectal bleeding (57\%), abdominal pain $(31 \%)$, change in bowel habits $(21 \%)$, weight loss $(11 \%)$, and anemia $(11 \%)^{1}$.

Younger patients present a clinically more advanced and biologically more aggressive disease. The most commonly found histologic type is mucinous adenocarcinoma with poorly differentiated signet ring cells $\mathbf{s}^{1,3-5}$. A retrospective review involving 180 patients younger than 50 years showed that, at the time of diagnosis, $37(21 \%)$ patients were in stage I, $47(26 \%)$ in stage II, 70 (39\%) in stage III, and $26(14 \%)$ in stage IV 1.

The majority of cases are sporadic tumors, as much in younger patients as in older; however, mutation analysis of younger patients, particularly for Lynch syndrome, the most common form of hereditary colorectal cancer, should be performed.

In this report, we present the case of a patient diagnosed with colorectal cancer at the age of 17 . Cases like this are rare in the literature; however, they support the statistics that show an increase in the incidence of this type of cancer in young patients.

\section{CASE REPORT}

A 17-year-old male patient, born and raised in Porto Alegre, arrived at the emergency room of Hospital de Clínicas de Porto Alegre complaining of abdominal pain and distension associated with nausea and vomiting for 1 month, weight loss ( $5 \mathrm{~kg}$ in 1 month), and diarrhea for 5 days without associated pathology. There was no family history of colorectal cancer. The patient was an alcoholic ( $1 \mathrm{~L}$ of vodka/day) for 1 year and a daily user of marijuana. Physical examination revealed a body mass index of $16 \mathrm{~kg} / \mathrm{m}^{2}$, distended abdomen, and shifting dullness but with no other abnormalities.

Laboratory tests showed normocytic and normochromic anemia. Serological tests for HIV and hepatitis B and C were negative.

Abdominal ultrasound confirmed voluminous ascites without changes in structure or hepatic vessel flow. Paracentesis was performed and $3.7 \mathrm{~L}$ of a citrine-colored liquid were removed. Cellularity was lymphocyte predominant and cytopathology was negative.

Computed tomography (CT) of abdomen was performed and identified a $5.9 \mathrm{~cm}$-long stenotic lesion in transverse colon causing upstream colonic distension; thickening of the ileocecal valve and of the walls of the terminal ileum; ileal and jejunal distension; and densification of greater omentum, transverse mesocolon and parietal peritoneum associated with ascites (figure 1).

Colonoscopy revealed a vegetating intraluminal lesion occupying $95 \%$ of the transverse colon cavity. Biopsies gave a histopathological diagnosis of ulcerated adenocarcinoma with poorly differentiated signet ring cells (figure 2). 


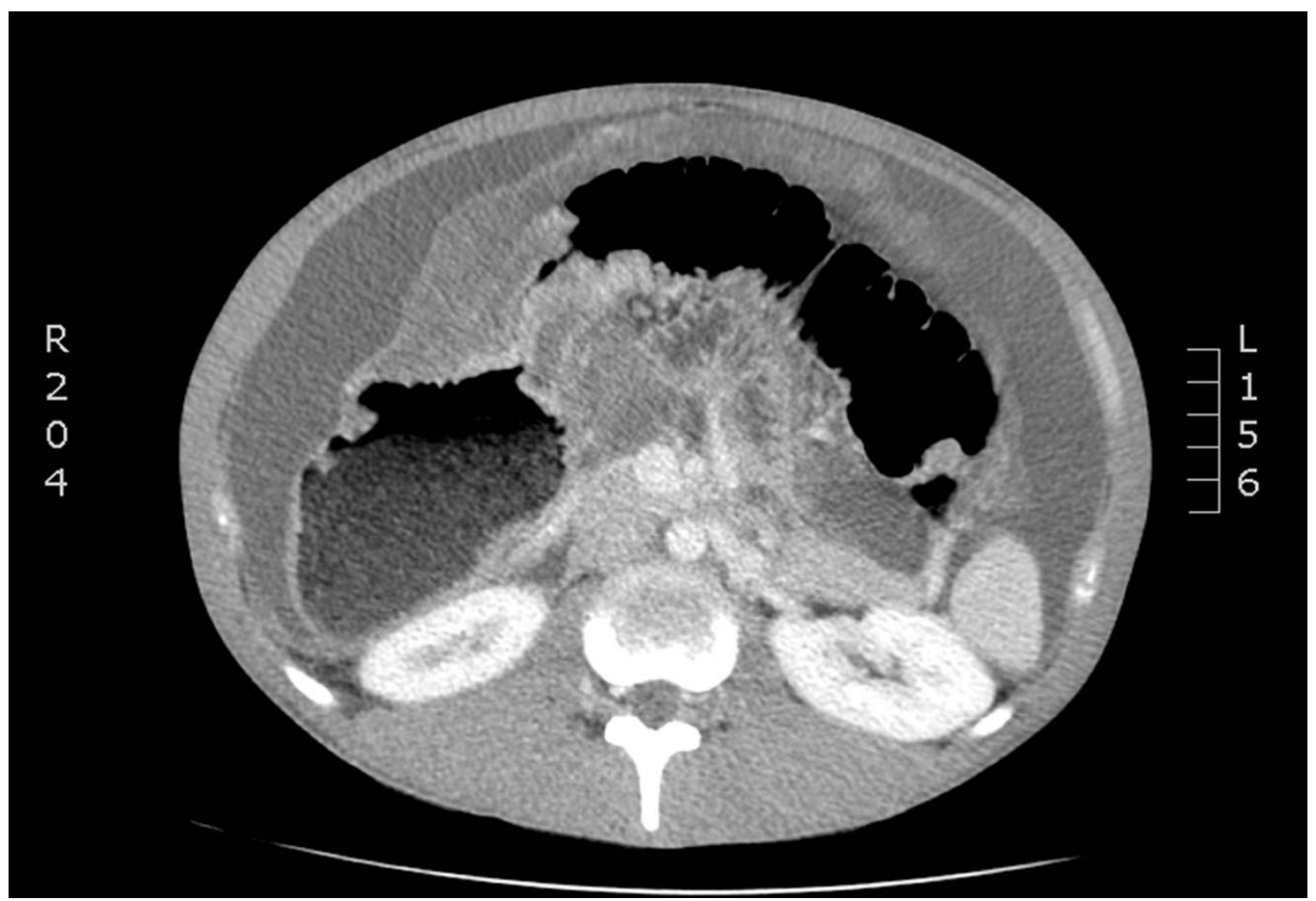

Figure 1: Computed tomographic with stenotic lesion in transverse colon.

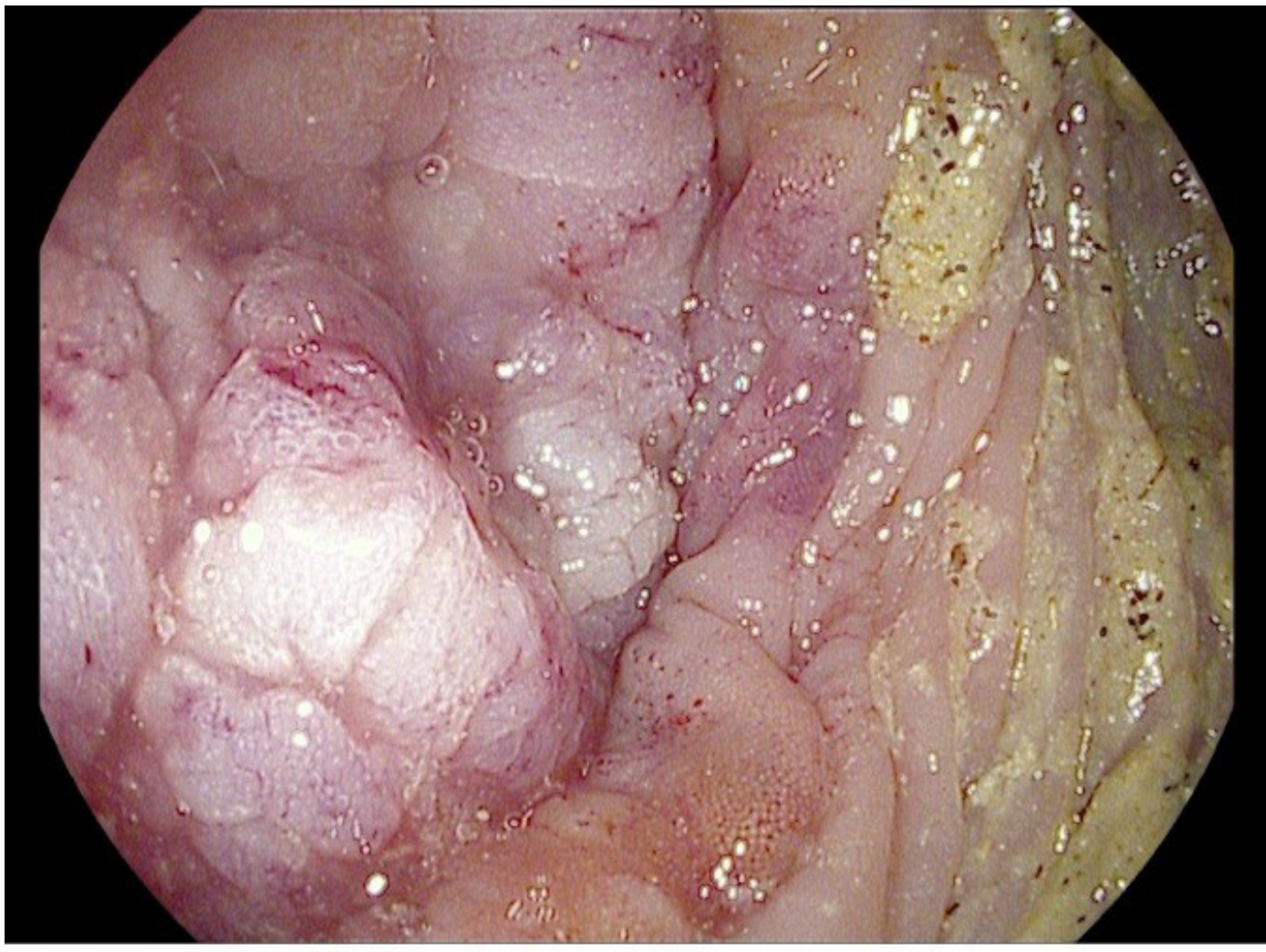

DATE:18/May/2015 0754.48 Doctor:DRAHELEACE
ID:132008293 COMNETI: ESPESSAMENTO NO TRMNEVERSO

Ans:17 Sex:M

Figure 2: Infiltrative lesion in transverse colon. 
Two days later, the patient developed intestinal obstruction and underwent an emergency laparotomy, right ileocolectomy, and ileocolic anastomosis. Among the operative findings there were ascites $(3200 \mathrm{~mL})$, tumor in the proximal transverse colon with thickening of the omentum, invasion of the greater gastric curvature, and peritoneal carcinomatosis. Pathological examination confirmed synchronous adenocarcinoma of ascending and transverse colon with metastases to cecal appendix and four lymph nodes, corresponding to surgical stage T4N2M1 (stage IV). A search for Lynch syndrome with mismatch repair immunohistochemistry of microsatellite instability of high-frequency MSH1, MSH2, MSH6, and PMS2 was negative. Chest CT was performed and showed no evidence of metastasis. Patient exhibited good postoperative evolution and after 1 month, at ECOG performance status 0 , underwent eight cycles of FOLFOX chemotherapy. Later there was progression of the disease: an increase in abdominal damage and intestinal obstruction, which led to death 7 months after diagnosis.

\section{DISCUSSION}

Colorectal cancer in patients younger than 30 years old corresponds to $1-2 \%$ of cases. Biologically, the disease seems to be more aggressive in young patients and $61.8 \%$ are in an advanced stage (stages III / IV) at the time of diagnosis. However, there seems to be no difference in survival when compared to older adults, probably because the younger population has fewer comorbidities and better performance in and tolerance to treatments ${ }^{3,4,6}$. Higher rates of peritoneal carcinosis as well as larger $(>5 \mathrm{~cm})$ and more infiltrative tumors are also reported in younger patients ${ }^{5}$.

Although most cases of colorectal neoplasia are sporadic, in this age group there is a greater incidence of gene mutations and genetic evaluation is recommended for Lynch syndrome by searching for microsatellite instability or examining immunohistochemistry for the presence of DNA repair proteins ( $\mathrm{MSH} 1, \mathrm{MSH} 2$, MSH6, and PMS2). The diagnosis of colorectal cancer in these patients modifies the follow-up of first-degree relatives ${ }^{7,8}$. A study comparing the presence of mutated Kirsten Ras (KRAS), BRAF, and $\mathrm{MSI}$ (microsatellite instability) genes, which may be associated with aggressive disease and in some cases provide information for treatment purposes, between patient groups under and over 40 years of age showed no statistically significant difference between the groups ${ }^{6}$. In the present case, colonoscopy did not reveal polyps or other findings indicative of familial adenomatous polyposis or inflammatory diseases. Work-up for Lynch syndrome was negative. Testing for KRAS and BRAF mutation was not performed.

Currently, there is a decrease in the incidence of colorectal cancer in patients older than 50 and an increase in incidence in those younger than 50 . This is probably related to screening of elderly patients, which makes the treatment of premalignant lesions possible at an earlier stage. The diagnosis in young people is often late since neoplasia is rarer in this age group and the symptoms tend to be attributed to benign pathologies. In light of the foregoing, it is necessary to pay close attention to symptoms in this population and conduct new studies to evaluate the possible benefits of performing early screening ${ }^{3,5-11}$.

\section{REFERENCES}

1. Myers EA, Feingold DL, Forde $\mathrm{KA}$, Arnell T, Jang JH, Whelan RL. Colorectal cancer in patients under 50 years of age: A retrospective analysis of two institutions' experience. World J Gastroenterol. 2013;19(34):56517. http://dx.doi.org/10.3748/wjg.v19. i34.5651. PMid:24039357.

2. Rêgo AGS, Borges ICV, Valença RJV, Teles JBM, Pinto LSS. Câncer colorretal em pacientes jovens. Rev Bras Cancerol. 2012;58(2):173-80.

3. Inra JA, Syngal S. Colorectal cancer in young adults. Dig Dis Sci. 2015;60(3):722-33. http://dx.doi. org/10.1007/s10620-014-3464-0. PMid:25480403.
4. Kneuertz PJ, Chang GJ, Hu CY, Rodriguez-Bigas MA, Eng C, Vilar E, et al. Overtreatment of young adults with colon cancer: more intense treatments with unmatched survival gains. JAMA Surg. 2015;150(5):4029. http://dx.doi.org/10.1001/ jamasurg.2014.3572. PMid:25806815.

5. Ciarrocchi A, Amicucci G. Sporadic carcinoma of the colon-rectum in young patients: a distinct disease? A critical review. J Gastrointest Cancer. 2013;44(3):264-9. http://dx.doi. org/10.1007/s12029-013-9507-5. PMid:23712253.

6. Vatandoust S, Price TJ, Ullah S, Roy AC, Beeke C, Young JP, et al. Metastatic colorectal cancer in young adults:a study from the South Australian population-based registry. Clin Colorectal Cancer. 2016;15(1):326. http://dx.doi.org/10.1016/j. clcc.2015.07.005. PMid:26341410.

7. Mork ME, You YN, Ying J, Bannon SA, Lynch PM, Rodriguez-Bigas MA, et al. High prevalence of hereditary cancer syndromes in adolescents and young adults with colorectal cancer. J Clin Oncol. 2015;33(31):35449. http://dx.doi.org/10.1200/ JCO.2015.61.4503. PMid:26195711.

8. Umar A, Boland CR, Terdiman JP, Syngal S, Chapelle A, Rüschoff J, et al. Revised Bethesda Guidelines for hereditary nonpolyposis colorectal cancer (Lynch syndrome) and 
microsatellite instability. $J$ Natl Cancer Inst. 2004;96(4):261-8. http:// dx.doi.org/10.1093/jnci/djh034. PMid:14970275.

9. Moreira L, Balaguer F, Lindor N, de la Chapelle A, Hampel H, Aaltonen LA, et al, EPICOLON Consortium. Identification of Lynch syndrome among patients with colorectal cancer.
JAMA. 2012;308(15):1555-65. http:// dx.doi.org/10.1001/jama.2012.13088 PMid:23073952.

10. Liang J, Kalady MF, Church J. Young age of onset colorectal cancers. Int $J$ Colorectal Dis. 2015;30(12):1653-7. http://dx.doi.org/10.1007/s00384-0152341-4. PMid:26358068.
11. Davis DM, Marcet JE, Frattini JC, Prather AD, Mateka JJ, Nfonsam VN. Is it time to lower the recommended screening age for colorectal cancer? J Am Coll Surg. 2011;213(3):35261. http://dx.doi.org/10.1016/j. jamcollsurg.2011.04.033. PMid:21737316.

Received: Dec 07, 2015 Accepted: Apr 13, 2016 